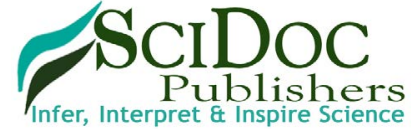

International Journal of Anesthesiology \& Research (IJAR)

ISSN 2332-2780

\title{
Effects of General Anesthesia vs Regional Anesthesia on Neonatal Outcomes: A Systemic Review and Mata Analysis
}

Mekonnen $\mathrm{S}^{1^{*}}$, Ahmed $\mathrm{S}^{2}$

${ }^{1}$ Department of Anesthesiology, College of Health and medical Sciences, Dilla University, Ethiopia.

${ }^{2}$ Dilla University Teaching and Referral Hospital, Gedeo Zone, Dilla, Ethiopia.

\section{Abstract}

Backgrounds: Types of anesthesia provision and perioperative patient cares are the main determinants of neonatal outcome in mothers undergo caesarean section. Body of evidence didn't clearly reveal which types of Anesthesia technique is associated with better neonatal outcomes in mothers who gave birth under spinal anesthesia than general anesthesia. The aim of this systemic review and meta-analysis was to compare neonatal outcomes in mothers who undergo caesarean section under general anesthesia and regional anesthesia.

Methods: We carried out a systemic search of the electronic databases of central, Medline, Embase, LILACS, AOLJ and others with PICO strategy for controlled clinical trials comparing neonatal outcomes under general and regional anesthesia. Twenty trials were identified for eligibility assessment, ten trials were selected for data extraction, and nine trials were finally included in the meta-analysis. All controlled clinical trials using regional and general anesthesia for ASA I-II term pregnant women coming for cesarean section in elective and semi-urgent condition were selected. Eligibility assessment was performed independently by the two review authors using a customized form, while discrepancies were resolved by consensus. The Data from individual trial were extracted and entered Review Manager for synthesis.

Results: Ten studies (782 participants) were included in this review. The Apgar score at one minute less than seven was better in spinal anesthesia as compared to General Anesthesia (OR=0.24, 95\% confidence interval (CI) 0.14 to $0.42,5$ trials, 548 participants). There was no significant association at $5^{\text {th }}$ minute Apgar score less than seven (OR $=-0.02,95 \%$ CI -0.09 to $0.05,3$ trials, 260 participants). There was significant mean difference between spinal and general anesthesia on neonatal mean Apgar score at $5^{\text {th }}$ minute ( $\mathrm{MD}=0.51,95 \%$ CI 0.14 to $0.88,5$ trials, 671 participants).

There was a significant mean difference on Umbilical artery and Venous PH when general anesthesia is compared with spinal anesthesia $(\mathrm{MD}=-0.01,95 \% \mathrm{CI}-0.002$ top -0.00 , one trial, 40 participants) and ( $\mathrm{MD}=-0.98,95 \% \mathrm{CI}-1.66$ to -0.30 , one trial, 40 participants).

Conclusion: Regional Anesthesia is superior over general Anesthesia in certain neonatal outcomes as depicted by the pooled analysis of individual trials. However, there should be further review with individual trials having high power and similar dosage and techniques as most of the individual trials in this review are low powered and different types of outcome assessment techniques.

Keywords: Anesthesia; Apgar Score; Umbilical Artery PH; Umbilical Vein PH; Controlled Clinical Trial.

Abbreviations: AOLJ: African on Line Journal; BMI: Body Mass Index; CI: Confidence Interval; CMA: Comprehensive Meta-Analysis; ENNS: Early Neonatal Neurologic Score; ICU: Intensive Care Unit; LILACS: literature In Health Science In Latin America and Caribbean; MN: Mean Deviation; NACS: Neurologic Adaptive Capacity Score; OR: Odd Ratio; Revman: Review Manager; RR: Relative Risk; SD: Standard Deviation; SMD: Standardized Mean Difference.

\section{*Corresponding Author:}

Semagn Mekonnen

Department of Anesthesiology, College of Health and medical Sciences, Dilla University, Ethiopia.

Tel: +251913864605

E-mail: semmek17@gmail.com

Received: April 19, 2016

Accepted: June 07, 2016

Published: June 09, 2016

Citation: Mekonnen S, Ahmed S (2016) Effects of General Anesthesia vs Regional Anesthesia on Neonatal Outcomes: A Systemic Review and Mata Analysis. Int J Anesth Res. 4(6), 261-271. doi: http://dx.doi.org/10.19070/2332-2780-1600057

Copyright: Mekonnen $\mathbf{S}^{\circ}$ 2016. This is an open-access article distributed under the terms of the Creative Commons Attribution License, which permits unrestricted use, distribution and reproduction in any medium, provided the original author and source are credited. 


\section{Background}

Obstetric Anesthesia is a demanding but challenging subspecialty of anesthesiology and it requires special skills because two lives are involved at the same time at any time of the day. The choice of Anesthesia, either general or regional Anesthesia, for cesarean section depends upon indication for operation, its urgency, and preference of patients, obstetrician and anesthetist [1,2]. Both general and spinal Anesthesia are not ideal for cesarean section because each has advantages and risk to fetus. However, the plan of anesthetist is to choose the method which is safest and most comfortable for the mother, least depressant to the newborn and which provides optimal working conditions for the obstetrician [2-4].

Spinal anesthesia affects neonates either by decreasing uteroplacental perfusion secondary to sympathetic blocked induced hypotension or intratecally administered Opioids with local anesthetics that depress the respiratory center and end up with asphyxia and acidosis [3, 4].

The effect of general anesthesia on neonate depends on intravenous agent, dosage of the agent and the total induction delivery time $[1,5]$.

According to a study conducted in India, the higher the induction delivery time the lower the Apgar score was in general anesthesia than regional anesthesia and the mean Early neonatal neurobehavioral score was higher in spinal $(30 \pm 1.3)$, general $(28.3 \pm 1.76$ and epidural $(28.4 \pm 1.93)$ respectively [5].

The effect of types of Anesthesia on neonatal outcomes is uncertain that some studies showed no difference in neonatal outcomes between regional and general Anesthesia [6, 7] and others showed that neonatal outcomes are better in regional Anesthesia than general Anesthesia [3-5, 8-20].

It is very important to know the types of Anesthesia with better neonatal outcomes despite the risks and benefits of each type of Anesthesia.

\section{Objective}

To compare effects of General Anesthesia and Regional Anesthesia on Neonatal outcomes.

\section{Criteria for Considering Studies for this Review}

\section{Types of study}

Randomized controlled trials.

\section{Types of participants}

ASA I and II full term pregnant women with no fetal distress and abnormality coming for elective or emergency cesarean section.

\section{Types of intervention}

Intervention: Babies delivered with cesarean section under regional Anesthesia (spinal, epidural or combined spinal-epidural).
Control: Babies delivered with cesarean section under General Anesthesia.

\section{Types of Outcomes}

Primary outcomes: The primary outcomes were Apgar score at first and fifth minute less than seven, Apgar score at first and fifth minute greater than seven, mean Apgar score at first and fifth minute and umbilical blood gas analysis.

Secondary outcomes: The secondary outcomes were Neurobehavioral Adaptive capacity Score, need for resuscitation, hypoglycemia and phototherapy.

\section{Search methods for identification of studies for the review}

Ethical clearance was obtained from Dilla University research and dissemination office. We carried out a systemic search of the electronic database: central, Medline, Embase, LILACS, AOLJ and others with PICO strategy as described in methodology.

The search was restricted to full reports of randomized controlled trials published in peer-reviewed journals without excluding trials published in languages other than English and no date restriction was applied up to April 2015. Trials studying ASA I and II mothers with no fetal distress coming for elective or emergency caesarean section were incorporated in the Meta analysis.

Eligibility assessment was performed independently by the two review authors using a customized form, while discrepancies were resolved by consensus. Two Authors independently assessed each trial for inclusion in the review using the information described in the section 'Criteria for considering studies for this review' and Studies that did not meet the inclusion criteria were excluded and the reason was stated in the table of 'Characteristics of excluded studies' (Table 2).

We prepared a flow diagram to summarize the study selection process according to PRISMA chart.

As it has been mentioned in methodology, the two Authors searched independently the five major databases and some others. Trials identified through the search were given a code depending on the topic. We searched the database for potential eligibility studies without year and language restriction with medical subject heading $(\mathrm{MeSH})$ terms of Neonate, Apgar, outcome, umbilical blood gas, Neonatal Adaptive capacity score and $\mathrm{Ph}$ as follows:

1. general

2. regional

3. spinal

4. epidural

5. \#1 and (\#2 or \#3 or \#4)

6. Anesthesia*

7. \#5 and \#6

8. cesarean section*

9. \#8 and \#9

10. random*

11. controlled-clinical-trial 
PRISMA Flow Chart

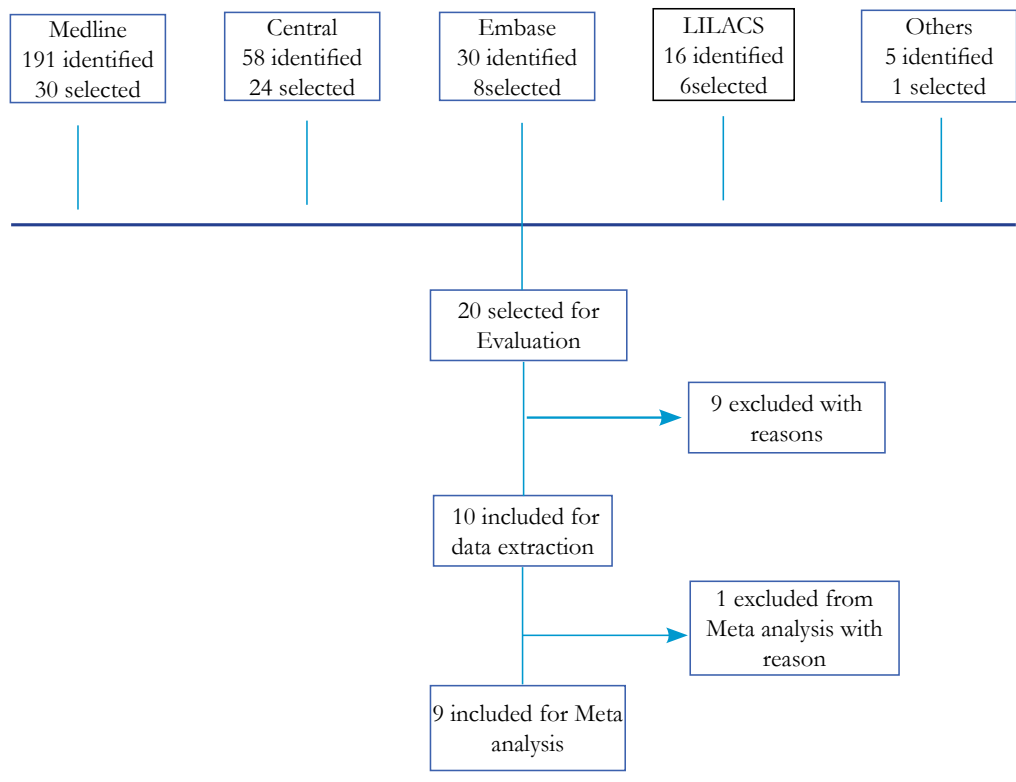

12. \#12 or \#13

13. \#11 and \#14

\section{Methods of the review}

Semagn Mekonnen (SM) selected potentially relevant trials from those identified by the search strategy and retrieved the full articles and multiple publications from the same data set were only used once. SM and Siraji Ahmed (SA) independently assessed each trial for inclusion in the review using the information described in the section Criteria for considering studies for this review. Studies that did not meet the inclusion criteria were excluded and the reasons were stated in the table of Characteristics of excluded studies. SM and SA independently assessed the methodological quality of the included trials which were measured by Generation of allocation sequence, allocation concealment, blinding and loss to follow up. For all trials, each quality component apart from blinding were classed as adequate, inadequate or unclear, (Table 1). For allocation concealment, the letters $\mathrm{A}$ to $\mathrm{D}$ were used: where $\mathrm{A}=$ adequate, $\mathrm{B}=$ unclear, $\mathrm{C}=$ inadequate and $\mathrm{D}=$ not used. For loss to follow up, inclusion of $90 \%$ of participants was considered adequate. Blinding was assessed using the following criteria: blinding of participants, blinding of Health care providers and blinding of outcome assessment. Blinding was assessed as open or single blind. Disagreements between Authors were resolved by discussion.

Statistical combination of data from two or more separate trials in a meta-analysis was decided based on the evaluation of the clinical and methodological heterogeneity. The inconsistency throughout trials were quantified with the $\mathrm{I}^{2}$ statistic proposed by Higgins and colleagues, assuming a value more than $50 \%$ as a substantial heterogeneity.

The summary effect measure were risk ratio (RR) and odd ratio for dichotomous variables and mean Difference and standard deviation for continuous variables along with their corresponding 95\% confidence intervals (CI). The meta-analysis was planned to be performed through a random-effects model and Mantel-
Haenszel $(\mathrm{M}-\mathrm{H})$ statistical method, anticipating that trials would have different techniques and assuming that the actual true effects have a normal distribution.

The data Analysis was conducted using Review Manager (RevMan 5.3, Cochrane Collaboration) and Comprehensive Meta-Analysis (CMA). This systematic review was carried out using the methods established by the Cochrane Handbook for Systematic Reviews of Interventions and we followed the recommendations and checklist items from the PRISMA Statement for Reporting Systematic Reviews and Meta-analysis.

\section{Description of studies}

The search strategies identified 300 trials from different data bases as mentioned in the methodology section (Figure 1). After a process of successive screening for eligibility, 20 studies were selected for more detail evaluation. With subsequent screening, 10 studies with 782 participants were included for analysis and the rest were excluded with reasons (Table 3).

The 10 studies analyzed were published between 1985- 2014 and they were performed in South America, Europe and Asia. The mean age of included studies ranged from 27-31years. Whereas the mean weight reported was $61-74 \mathrm{~kg}$ in four studies. The BMI of included studies was reported in four studies which were ranged from $25.4-29 \mathrm{~kg} / \mathrm{m}^{2}$. Sample size ranged from $52-188$ participants and only two studies had large sample size of 160 and 188. In six studies the neonatal outcomes were compared with General and spinal Anesthesia where as general, spinal and epidural anesthesia was compared for neonatal outcomes in three studies. Only one study compared neonatal outcomes with General and epidural Anesthesia.

General Anesthesia was induced with $4-6 \mathrm{mg} / \mathrm{kg}$ thiopental and $1.5-2 \mathrm{mg} / \mathrm{kg}$ succinylcholine in nine studies. Only one study was performed with propofol intravenous agent. Spinal Anesthesia was conducted with $0.5 \%-0.75 \%$ bupivacaine. The details were described in tables of excluded studies (Table 3). 
Table 1. Description of included studies. GA: general Anesthesia; SA: spinal Anesthesia; Ep: epidural Anesthesia; ${ }^{*}$ Spinal alone; Thio: thiopental; Bupi: bupivacaine; Fent: fentanyl; succ: succinylcholine; UA: umbilical Artery; UV: Umbilical vein; NACS: neurologic Adaptive Capacity Scores, ${ }^{* *}$ epidural Alone.

\begin{tabular}{|c|c|c|c|c|c|}
\hline Study groups & sample (n) & county & GA groups & SA and or EP groups & outcome variables \\
\hline $\begin{array}{c}\text { Arif Yeuun and } \\
\text { Colleagues }\end{array}$ & 62 & Turkey & $5 \mathrm{mg} / \mathrm{kg}$ thio $1.5 \mathrm{mg}: \mathrm{kg}$ succ & EP: $15 \mathrm{~m} 1$ of $0.5 \%$ bupi** & Apgar score, UA, UV \\
\hline $\begin{array}{c}\text { Kosam Durga and } \\
\text { Colleagues }\end{array}$ & 60 & India & $\begin{array}{l}\text { thio } 4-5 \mathrm{mg} / \mathrm{kg}+2 \mathrm{mg} / \mathrm{kg} \text { succ } \\
\text { SA: } 0.5 \% \text { of } 2.2-2.5 \mathrm{ml} \text { bupi }\end{array}$ & EP: $12 \mathrm{~m} 1$ of $0.5 \%$ bupi & Apgar score, UA, UV, NACS \\
\hline $\begin{array}{l}\text { Akyol A and } \\
\text { Colleagues }\end{array}$ & 62 & Holland & $5 \mathrm{mg} / \mathrm{kg}$ thio $+1.5 \mathrm{mg} / \mathrm{kg}$ succ & $\begin{array}{c}0.5 \% \text { of } 1.6 \mathrm{ml} \text { bupi and } \\
20 \mu \mathrm{g} \text { fent* }\end{array}$ & Apgar scores, UA, UV \\
\hline $\begin{array}{l}\text { Aftab Imtiaz and } \\
\text { Colleagues }\end{array}$ & 30 & Pakistan & $\begin{array}{c}\text { thio } 4-5 \mathrm{mg} / \mathrm{kg}+1.5 \mathrm{mg} / \mathrm{kg} \\
\text { succ }\end{array}$ & $0.5 \%$ of $3 \mathrm{ml}$ bupi & Apgar scores, UA, UV \\
\hline $\begin{array}{l}\text { Saeed Ahmed and col- } \\
\text { leadgues }\end{array}$ & 160 & pakistan & $\begin{array}{c}\text { propofol 2mgrkg }+1.5 \mathrm{mg} / \\
\mathrm{kg} \mathrm{succ}\end{array}$ & $0.5 \%$ of $1.5 \mathrm{ml}$ bupi & Apgar scores, UA, UV \\
\hline $\begin{array}{c}\text { Saleem Sabbar and } \\
\text { Colleagues }\end{array}$ & 100 & Pakistan & not described & $0.5 \%$ of $1.5 \mathrm{ml}$ bupi & Apgar scores \\
\hline $\begin{array}{l}\text { Anil Ice and } \\
\text { Colleagues }\end{array}$ & 100 & turkey & $\begin{array}{c}\text { thio 4-5mgIIcg }+1.5 \mathrm{mg} \text {, } \mathrm{kg} \\
\text { suc }\end{array}$ & $0.5 \%$ of $2.2 \mathrm{ml}$ bupi* & Apgar scores, NICU \\
\hline $\begin{array}{l}\text { Rumina and } \\
\text { Colleagues }\end{array}$ & 100 & Pakistan & not described & $1.5 \mathrm{~m} 1$ bupi* & Apgar scores \\
\hline ABBOUD TK and & 52 & USA & thio $4-5 \mathrm{mg} / \mathrm{kg}+1.5 \mathrm{mtkg}$ succ & $0.5 \%$ of $2.2 \mathrm{ml}$ bupi* & Apgar scores, UA, UV, NACS \\
\hline Kolatat $\mathrm{T}$ and & 341 & Thailand & $\begin{array}{l}\text { thio } 4-5 \mathrm{mg} / \mathrm{kg}+1.5 \mathrm{mg} / \mathrm{kg} \\
\text { succ }\end{array}$ & $0.5 \%$ of $2.2 \mathrm{ml} \mathrm{bupi*}$ & Apgar scores, U.A, UV, NACS \\
\hline
\end{tabular}

Table 2. Risk of Bias within studies. A: low risk; B: High risk; C: uncertain/unclear risk of bias. Jadal scale.

\begin{tabular}{|c|c|c|c|c|c|c|c|c|c|}
\hline \multirow{2}{*}{ Study Scale } & \multirow{2}{*}{$\begin{array}{l}\text { sequence } \\
\text { generation }\end{array}$} & \multirow{2}{*}{$\begin{array}{l}\text { allocation } \\
\text { concealment }\end{array}$} & \multirow{2}{*}{ blinding } & \multirow{2}{*}{$\begin{array}{l}\text { incomplete } \\
\text { outcome data }\end{array}$} & \multirow{2}{*}{$\begin{array}{c}\text { selective } \\
\text { outcome } \\
\text { Reporting }\end{array}$} & \multirow{2}{*}{$\begin{array}{l}\text { free of } \\
\text { their bias }\end{array}$} & \multicolumn{3}{|c|}{ Jadal } \\
\hline & & & & & & & randamization & blinding & withdrawal \\
\hline $\begin{array}{c}\text { Arif Yeuun and } \\
\text { Colleague }\end{array}$ & A & $\mathrm{C}$ & C & A & A & A & 1 & 1 & 0 \\
\hline $\begin{array}{c}\text { Kosam Durga and } \\
\text { Colleagues }\end{array}$ & A & A & C & A & A & A & 2 & 1 & 0 \\
\hline $\begin{array}{c}\text { Akyol A and Col- } \\
\text { leagues }\end{array}$ & A & C & C & A & A & A & 1 & 1 & 0 \\
\hline $\begin{array}{c}\text { Aftab Imtiaz and } \\
\text { Colleagues }\end{array}$ & A & $\mathrm{C}$ & C & C & C & A & 1 & 1 & 0 \\
\hline $\begin{array}{c}\text { Saeed Ahmed and } \\
\text { colleadgues }\end{array}$ & A & A & C & A & A & A & 2 & 1 & 0 \\
\hline $\begin{array}{c}\text { Saleem Sabbar and } \\
\text { Colleagues }\end{array}$ & A & C & C & A & A & A & 2 & 1 & 0 \\
\hline $\begin{array}{c}\text { Anil İçel and Col- } \\
\text { leagues }\end{array}$ & A & C & $\mathrm{C}$ & A & A & A & 1 & 1 & 0 \\
\hline $\begin{array}{c}\text { Rumina and Col- } \\
\text { leagues }\end{array}$ & A & C & C & A & A & C & 1 & 1 & 0 \\
\hline $\begin{array}{l}\text { ABBOUD TK } \\
\text { and Colleagues }\end{array}$ & C & $\mathrm{C}$ & $\mathrm{C}$ & A & A & B & 1 & 1 & 0 \\
\hline $\begin{array}{c}\begin{array}{c}\text { Kolatat } \mathrm{T} \text { and } \mathrm{Col}- \\
\text { leagues }\end{array} \\
\end{array}$ & A & C & A & A & A & A & 2 & 2 & 0 \\
\hline
\end{tabular}

Tables 3. Characteristics of excluded studies.

\begin{tabular}{|c|c|}
\hline Study & Reason for exclusion \\
\hline MUHAMMAD A. 2004 & Randomization was not done and mothers were with severe preeclampsia \\
\hline Moslemi F. 2007 & Randomization was not done and mothers were with severe preeclampsia \\
\hline Shusee V. 2005 & Randomization was not done and mothers were with severe preeclampsia \\
\hline Suman C. 2013 & Randomization was not done and mothers were with severe preeclampsia \\
\hline Jawad Zahir 2011 & Randomization was not done; study not controlled trial (cohort study design) \\
\hline Charles S 2009 & Randomization was not done; study not controlled trial (cohort study design) \\
\hline TC Martin 2007 & Randomization was not done; study not controlled trial (cohort study design) \\
\hline G. Tonni 2006 & Randomization was not done; study not controlled trial (cohort study design) \\
\hline Sousan Rasooli 2013 & Randomization was not done; study not controlled trial (cohort study design) \\
\hline
\end{tabular}




\section{Results}

\section{Primary outcomes}

The immediate outcomes of neonates were assessed with Apgar score and umbilical blood gas analysis and that was why the included studies primary outcomes were Apgar score and Umbilical blood gas analysis results. The 10 included studies reported the $1^{\text {st }}$ and $5^{\text {th }}$ minute Apgar scores and of which five studies $[3,5,8-10]$ reported as mean \pm SD whereas the rest five reported as range of values. Neonatal umbilical blood gas was reported in five studies $[4,6,7,9,11]$. In six studies $[3,4,8,10,11$, 14] the first minute Apgar score is better in spinal anesthesia than general anesthesia whereas there were no significant different in the first minute Apgar score in two studies [6,7] in whichever type of Anesthesia, general vs regional (spinal and epidural). In only one study [4], the Fifth minute Apgar score was better in spinal anesthesia whereas there were no difference in nine studies on the fifth minute Apgar score. The umbilical blood gas analysis were not significantly different in three studies $[4,10,14]$ under general and spinal anesthesia. However, the blood gas analysis were better in regional anesthesia than general anesthesia in two studies $[6,7]$.

\section{Secondary outcomes}

Neonatal neurobehavioral response: The neonatal neurobehavioral response was reported in three studies with different assessment tools. Two studies reported neonatal neurobehavioral response with neonatal adaptive capacity score $[10,11]$ which was measured at 15 minute, $2 \mathrm{hrs}$ and $24 \mathrm{hrs}$ and babies delivered under general anesthesia had lower NACS as compared to Epidural and spinal groups but there were no difference at $24 \mathrm{hrs}$ where as one study reported with Early Neonatal Neurobehavioral Score [5].

Neonatal ICU Admission: Neonatal ICU admission was reported only in one study [9]. The numbers of neonates admitted to Neonatal ICU were higher in spinal $6(12 \%)$ as compared to general anesthesia which was $5(10 \%)$ neonates.

Figure 1. Forest plot for Apgar score at 1 minute $<7$ comparing SA VS GA: individual trials and Meta-analysis. Events, the total numbers with the events total: the total number of participants in intervention (SA) and control (GA). Weight: sample size contribution of the study relative to the pooled sample size of the meta-analysis. M-H, Mantel-Haenszel methods.

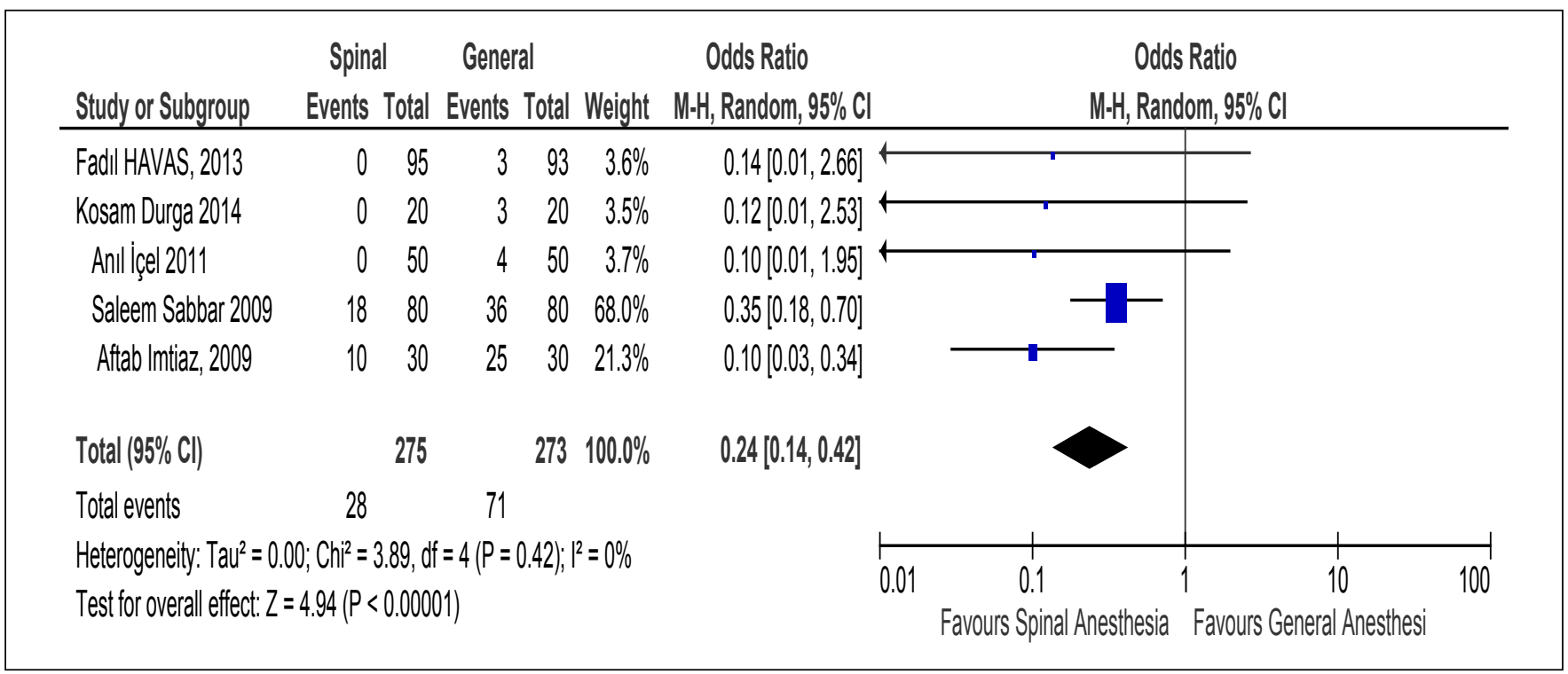

Figure 2. Forest plot for Apgar score at 5 minute $<7$ comparing SA VS GA: individual trials and Meta analysis. Events, the total numbers with the events total: the total number of participants in intervention (SA) and control (GA). Weight: sample size contribution of the study relative to the pooled sample size of the meta-analysis. M-H, Mantel-Haenszel methods.

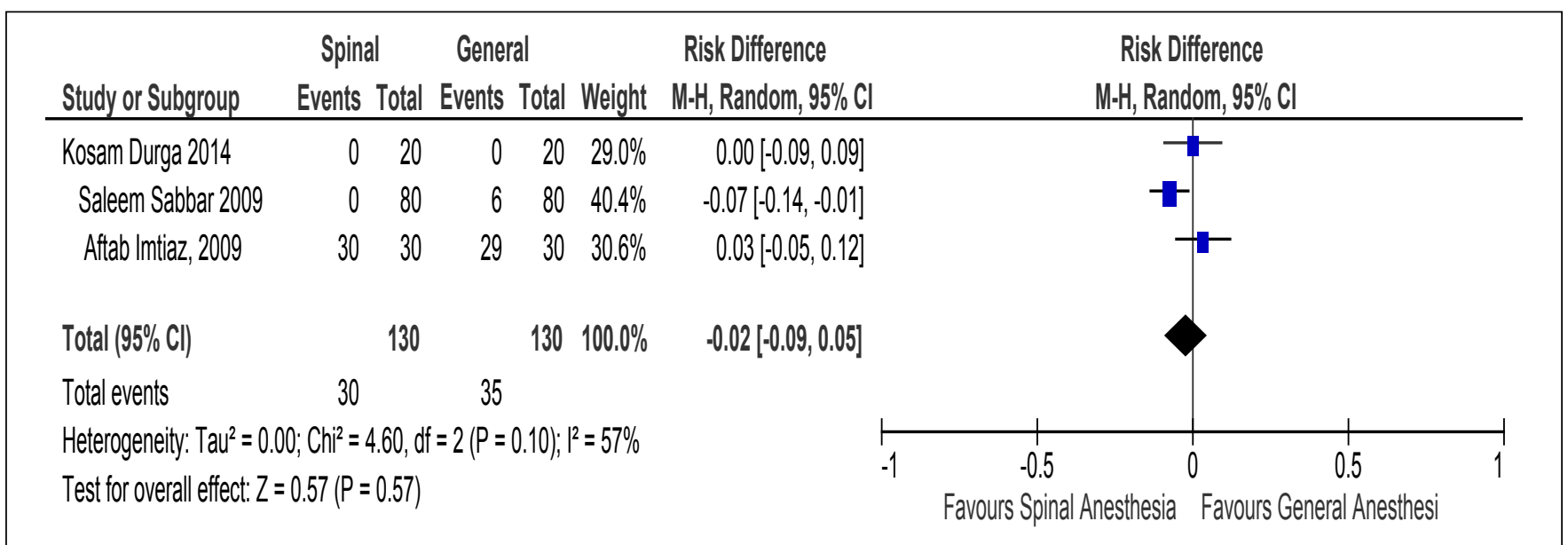


Figure 3. Forest plot for Apgar score at 1 minute $>7$ comparing SA VS GA: individual trials and Meta-analysis. Events, the total numbers with the events total: the total number of participants in intervention (SA) and control (GA). Weight: sample size contribution of the study relative to the pooled sample size of the meta-analysis. M-H, Mantel-Haenszel methods.

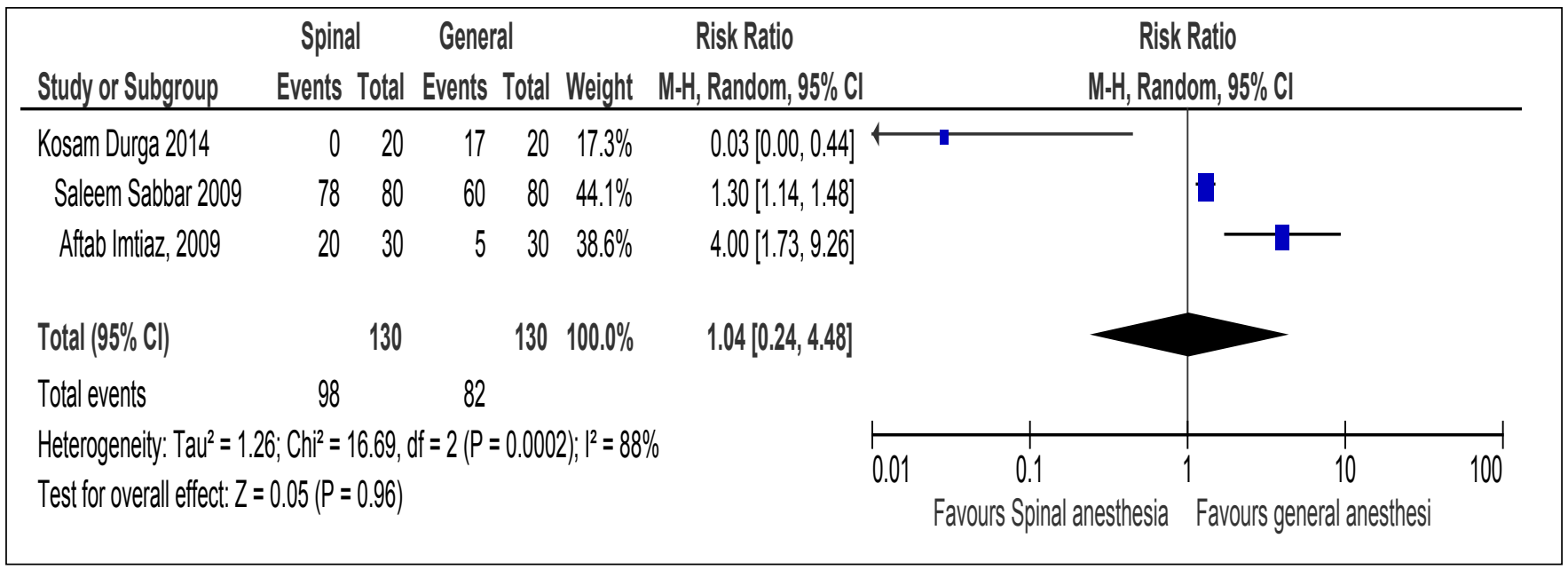

Figure 4. Forest plot for Apgar score at 5 minute $>7$ comparing SA VS GA: individual trials and Meta-analysis. Events, the total numbers with the events total: the total number of participants in intervention (SA) and control (GA). Weight: sample size contribution of the study relative to the pooled sample size of the meta-analysis. M-H, Mantel-Haenszel methods.

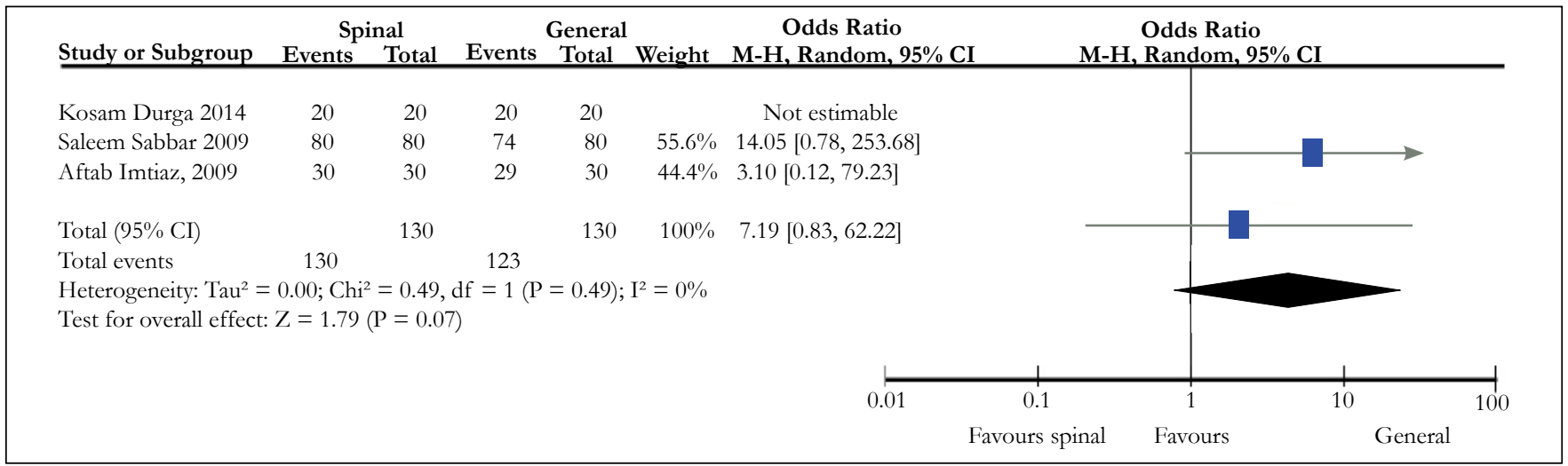

Figure 5. Forest plot for mean Apgar score at 1 minute comparing SA VS GA: individual trials and Meta-analysis. Total: the total number of participants in intervention (SA) and control (GA). Weight: sample size contribution of the study relative to the pooled sample size of the meta-analysis. IR: inverse variance.

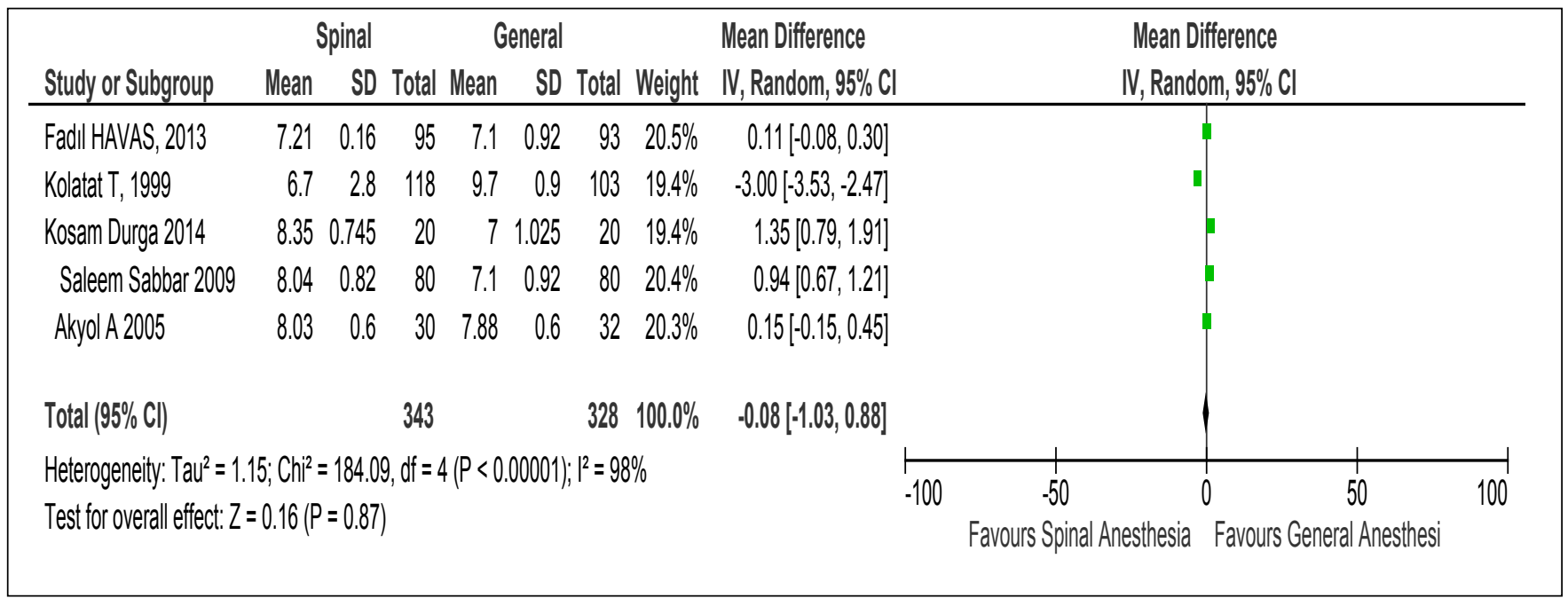


Figure 6. Forest plot for mean Apgar score at 5 minute comparing SA VS GA: individual trials and Meta-analysis. Total: the total number of participants in intervention (SA) and control (GA). Weight: sample size contribution of the study relative to the pooled Sample size of the meta-analysis. IR: inverse variance.

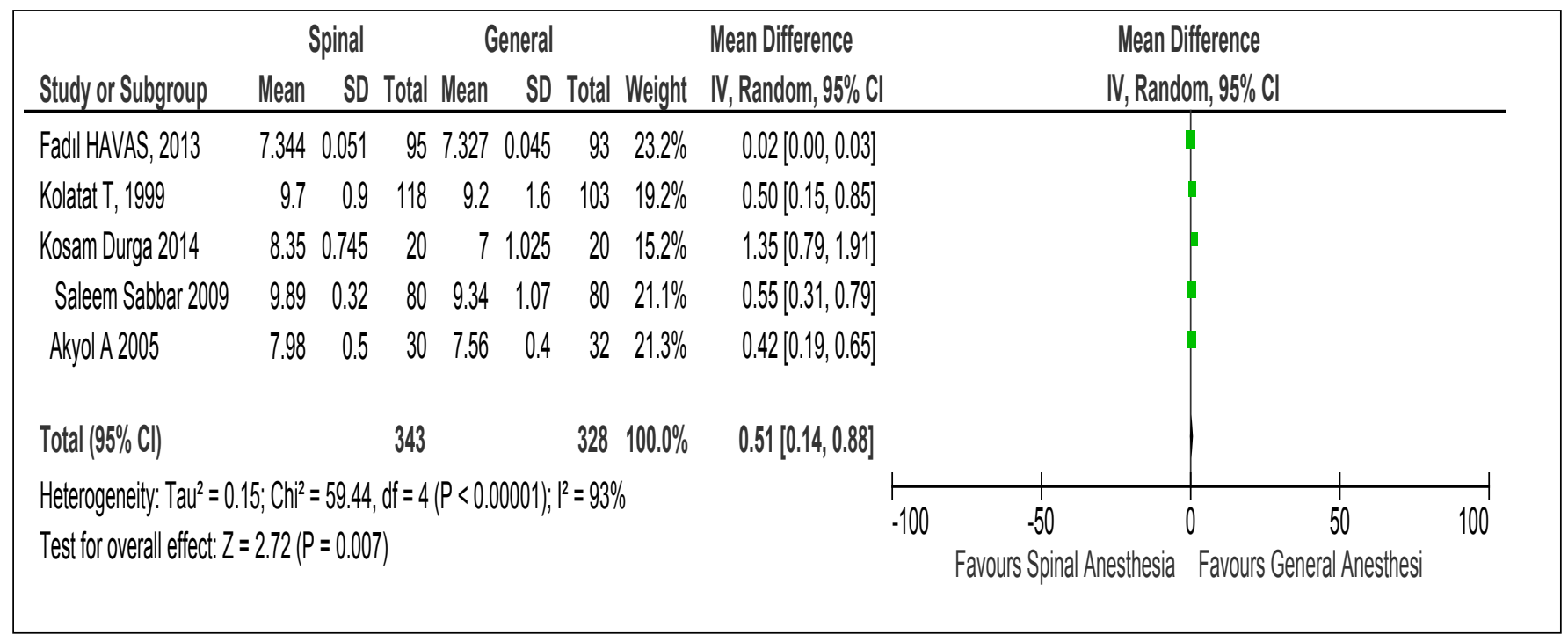

Figure 7. Forest plot for mean Apgar score at 1 minute comparing EA VS GA: individual trials and Meta-analysis. Total: the total number of participants in intervention (SA) and control (GA). Weight: sample size contribution of the study relative to the pooled sample size of the meta-analysis. IR: inverse variance.

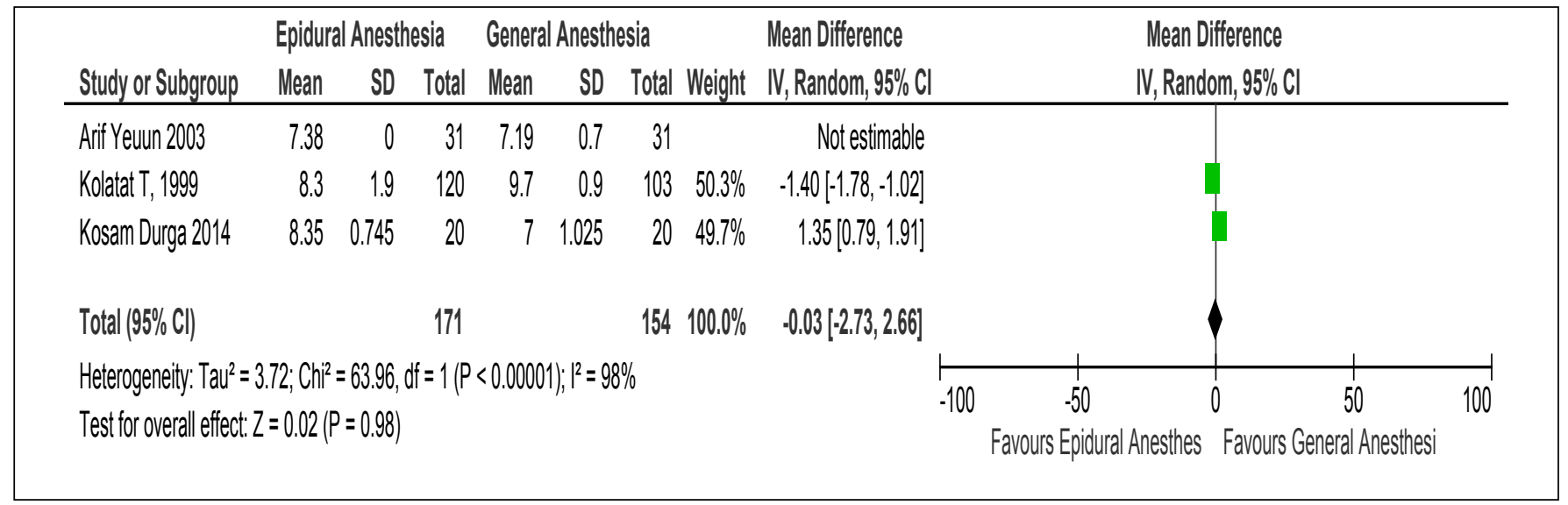

Figure 8. Forest plot for mean Apgar score at $5^{\text {th }}$ minute comparing EA VS GA: individual trials and Meta-analysis. Total: the total number of participants in intervention (SA) and control (GA). Weight: sample size contribution of the study relative to the pooled sample size of the meta-analysis. IR: inverse variance.

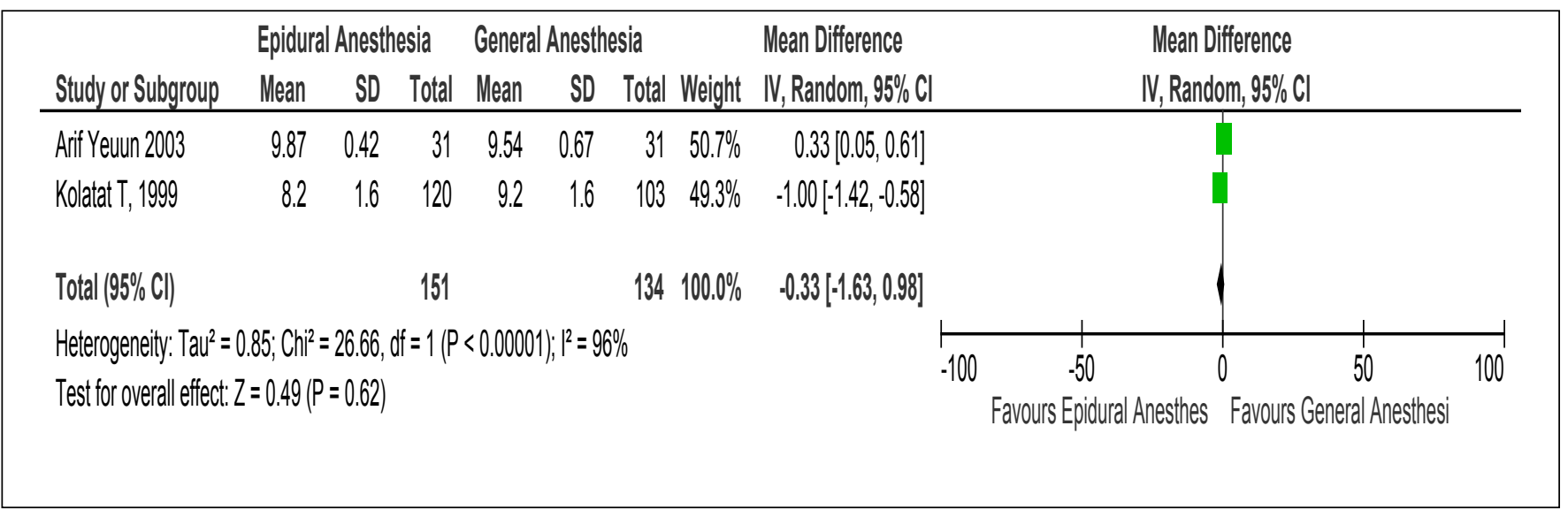


Figure 9. Forest plot for mean neonatal $\mathrm{PO}_{2}$ comparing SA VS GA: individual trials and Meta analysis. Total: the total number of participants in intervention (SA) and control (GA). Weight: sample size contribution of the study relative to the pooled sample size of the meta-analysis. IR: inverse variance.

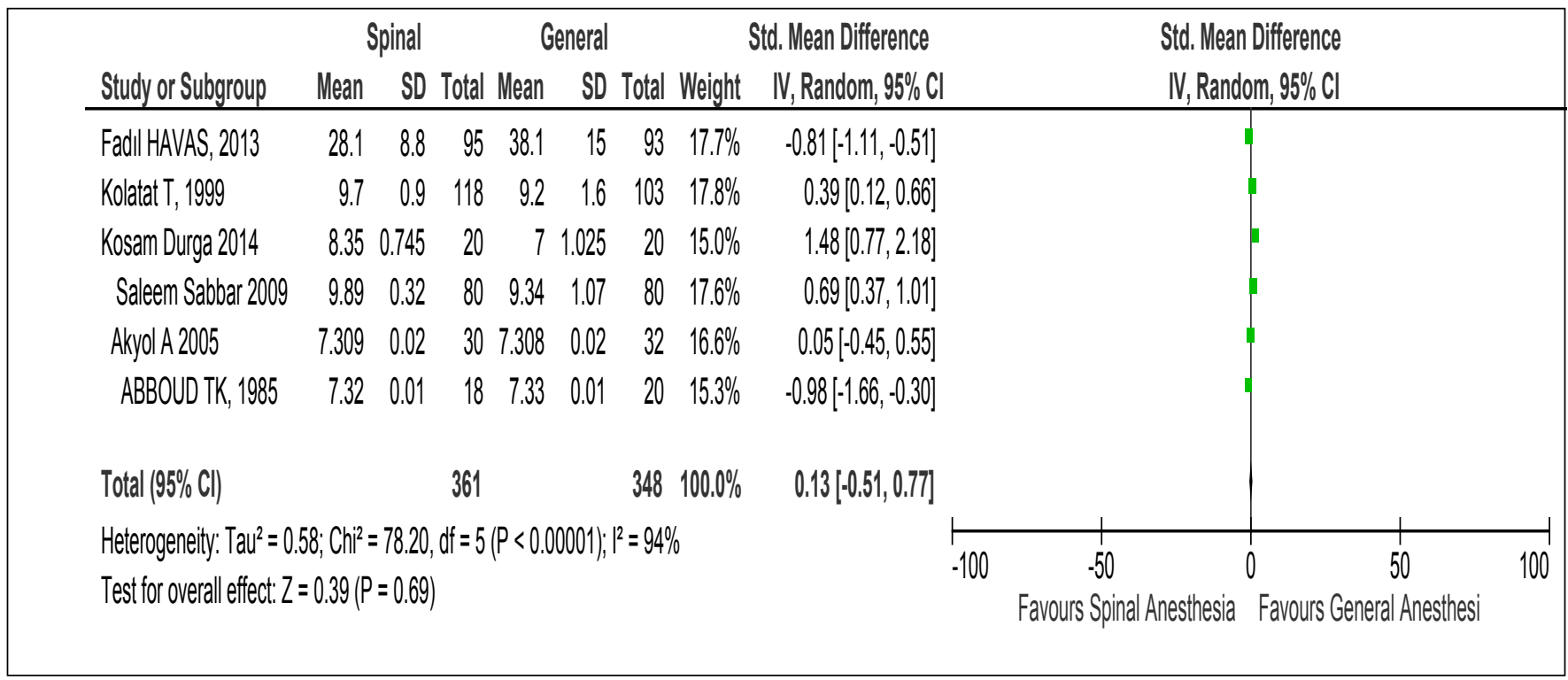

Figure 10. Forest plot for mean neonatal Umblical Artery PH comparing SA VS GA: individual trials and Meta-analysis. Total: the total number of participants in intervention (SA) and control (GA). Weight: Sample size contribution of the study relative to the pooled sample size of the meta-analysis. IR: inverse variance.

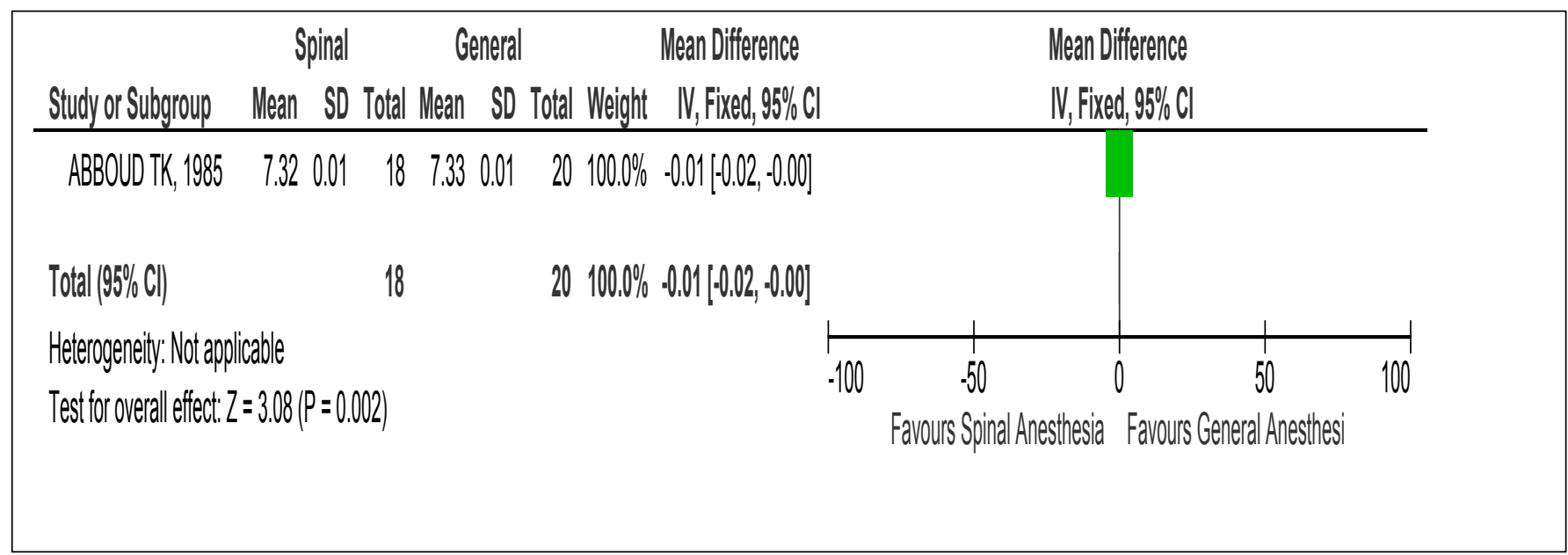

Figure 11. Forest plot for mean ENNS comparing SA VS GA: individual trials and Meta-analysis. Total: the total number of participants in intervention (SA) and control (GA). Weight: sample size contribution of the study relative to the pooled sample size of the meta-analysis. IR: inverse variance.

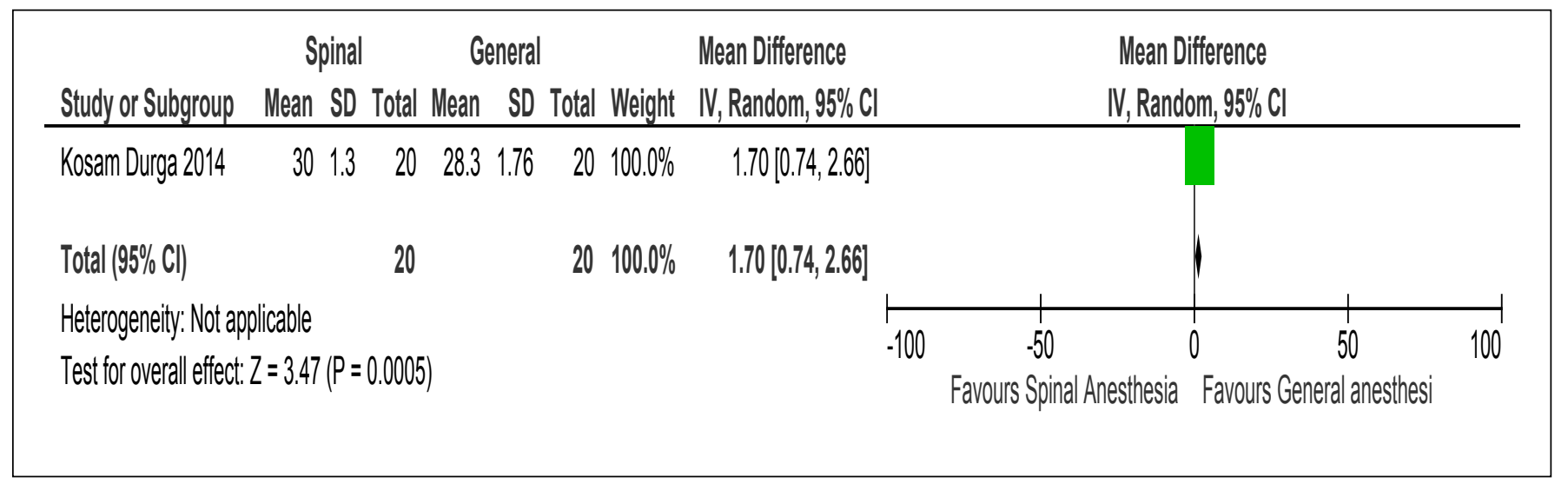


Figure 12. Forest plot for mean NACS at 15 minute comparing SA VS GA: individual trials and Meta analysis. Total: the total number of participants in intervention (SA) and control (GA). Weight: sample size contribution of the study relative to the pooled sample size of the meta-analysis. IR: inverse variance.

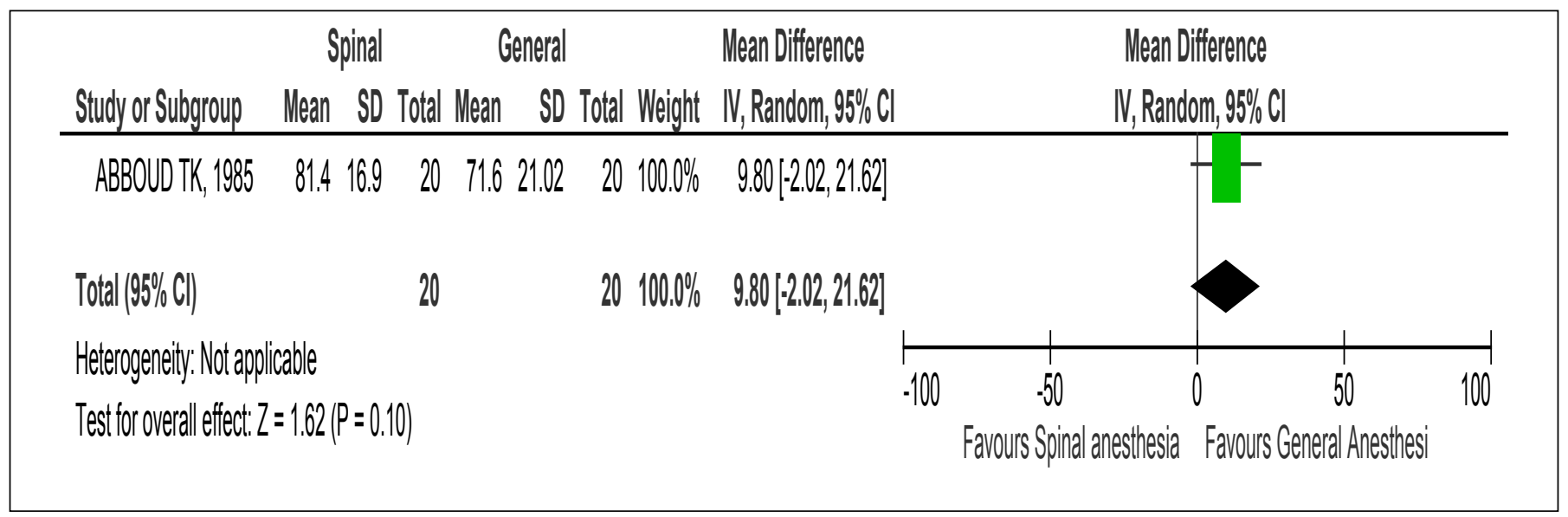

Figure 13. Forest plot for mean NACS at 2hrs comparing SA VS GA: individual trials and Meta analysis. Total: the total number of participants in intervention (SA) and control (GA). Weight: sample size contribution of the study relative to the pooled sample size of the meta-analysis. IR: inverse variance.

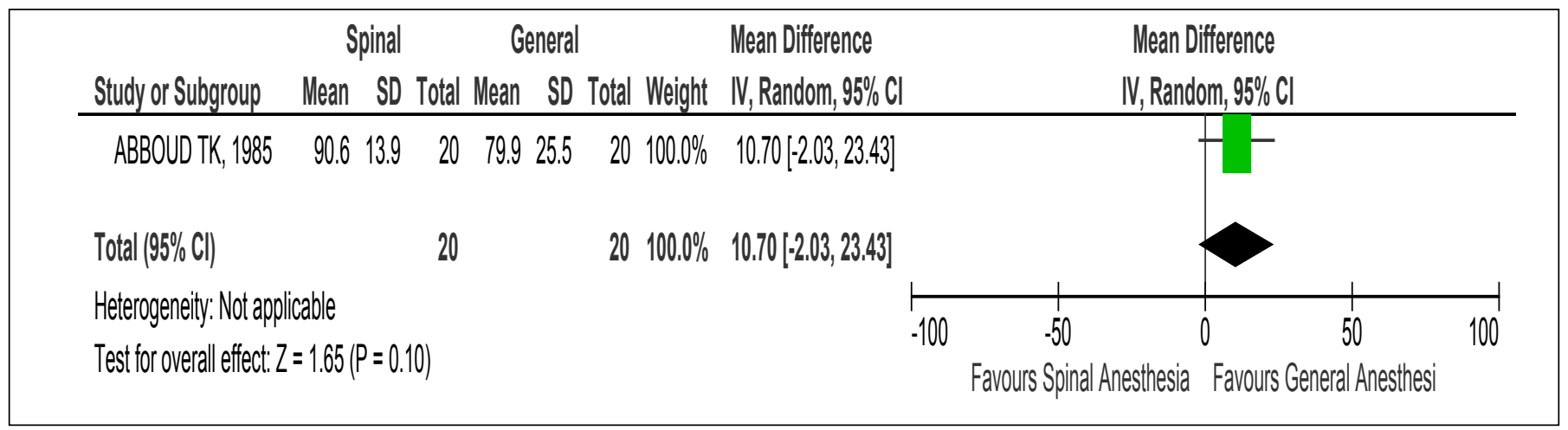

Figure 14. Forest plot for mean NACS at 24 hrs comparing SA VS GA: individual trials and Meta-analysis. Total: the total number of participants in intervention (SA) and control (GA). Weight: sample size contribution of the study relative to the pooled sample size of the meta-analysis. IR: inverse variance.

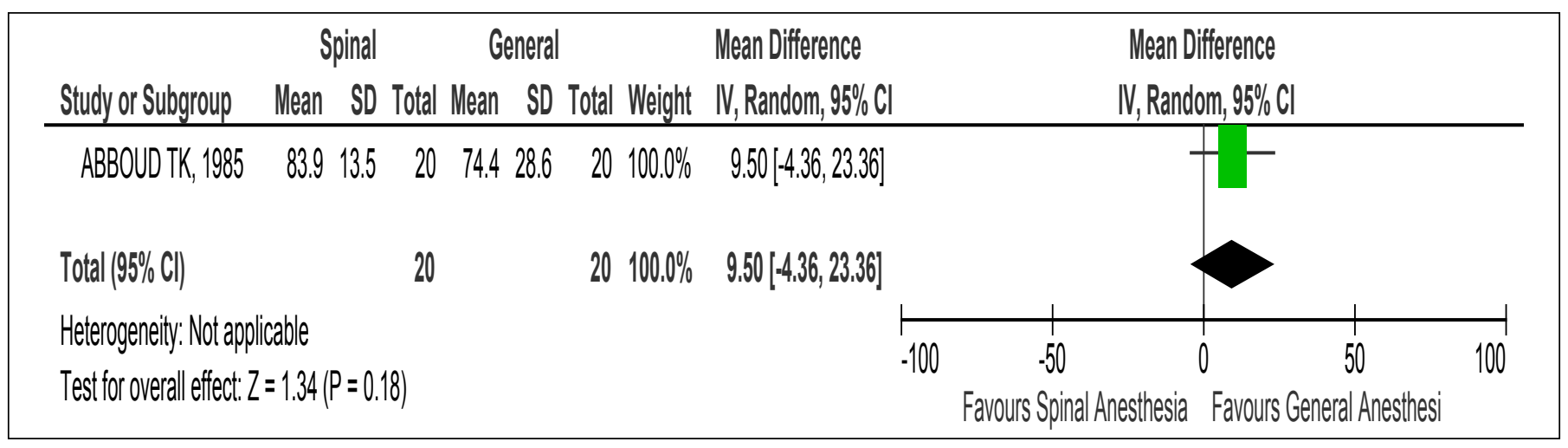

Respiratory support: Respiratory support requirement to neonate was reported in one study [14] and there was no significant difference between General anesthesia 4 (4.4\%) and Spinal anesthesia groups $4(4.2 \%)$.

Hypoglycemia and phototherapy: Incidence of hypoglycemia and requirement of phototherapy were reported in one study [14] and there was no significant difference between neonates delivered with general or spinal Anesthesia.

Requirement of resuscitation: Requirement of neonatal resuscitation at birth was reported in one study [5] and three babies out of twenty required resuscitation at birth who delivered with General Anesthesia as compared to Spinal and Epidural anesthesia who didn't require resuscitation at all.

\section{Quantitative data synthesis}

Regional Anesthesia and General anesthesia were compared as intervention and control respectively using Apgar score and umbilical blood gas analysis as the primary outcomes. Nine 
studies were included for meta-analysis.

In the pooled Analysis, The Apgar score at one minute less than seven was better in spinal anesthesia when compared to General Anesthesia (OR $=0.24,95 \%$ confidence interval (CI) 0.14 to 0.42 , 5 trials, 548 participants) [3, 5, 8, 9, 14] (Figure 1). However, there was no significant association at $5^{\text {th }}$ minute Apgar score less than seven $(\mathrm{OR}=-0.02,95 \% \mathrm{CI}-0.09$ to $0.05,3$ trials, 260 participants) $[3,5,8]$ (Figure 2).

There was no significant association between spinal and general anesthesia on neonatal Apgar score at $1^{\text {st }}$ and $5^{\text {th }}$ minute greater than seven $(\mathrm{OR}=1.04,95 \%$ CI 0.24 to $4.48,3$ trials, 260 participants) and (OR=7.19, 95\% CI 0.83 to 62.22, 3 trial, 260 participants) respectively $[3,5,8]$ (Figure $3 \& 4$ ).

There was no significant mean difference on neonatal mean Apgar score at $1^{\text {st }}$ and $5^{\text {th }}$ minutes between spinal and General anesthesia ( $\mathrm{MD}=-0.08,95 \% \mathrm{CI}-1.03$ to $0.88,5$ trials, 671 participants) $[3,5,7,11,14]$ (Figure 5). However, there was significant mean difference between spinal and general anesthesia on neonatal mean Apgar score at $5^{\text {th }}$ minute $(\mathrm{MD}=0.51,95 \%$ CI 0.14 to 0.88 , 5 trials, 671 participants) $[3,5,7,11,14]$ (Figure 6).

There was no significant mean difference between Epidural and General Anesthesia on neonatal mean Apgar score at $1^{\text {st }}$ and $5^{\text {th }}$ minutes $(\mathrm{MD}=-0.03,95 \% \mathrm{CI}-1.03$ to $2.66,3$ trials, 325 participants) $[5,6,11]$ (Figure 7 ) and $(\mathrm{MD}=-0.33,95 \% \mathrm{CI}-1.63$ to $0.98,2$ trials, 285 participants) respectively $[6,11]$ (Figure 8 ).

Six studies reported on neonatal umbilical arterial oxygen tension and noted that there was no difference in the standard mean difference (SMD) of umbilical arterial oxygen tension when general anesthesia is compared with spinal anesthesia (SMD= $0.13,95 \%$ CI -0.51 to $0.77,6$ trials, 709 participants) $[3,5,7,10$, 11, 14] (Figure 9). One study reported on umbilical artery and Venous $\mathrm{PH}$ and noted that there was a mean difference when general anesthesia is compared with spinal anesthesia $\mathrm{MD}=$ $-0.01,95 \%$ CI -0.002 top -0.00 , one trial, 40 participants) and (MD $=-0.98,95 \%$ CI -1.66 to -0.30 , one trial, 40 participants) [10] (Figure 10).

One study reported Early Neonatal Neurobehavioral Score (ENNS) and noted that there was a significant mean difference when general anesthesia is compared with spinal anesthesia (MD $=1.70,95 \%$ CI 0.24 to 2.66 , one trial, 40 participants) [5] (Figure 11).

One study reported neonatal neurobehavioral Adaptive capacity score (NACS) in 15 minutes, $2 \mathrm{hrs}$ and $24 \mathrm{hrs}$ and noted that there were no difference when general anesthesia is compared with general anesthesia (MD $=9.8,95 \% \mathrm{CI}-2.02$ to 21.62, one trial, 40 participants), $(\mathrm{MD}=10.70,95 \% \mathrm{CI}-2.03$ to 23.43 , one trial, 40 participants) and $(\mathrm{MD}=9.5,95 \% \mathrm{CI}-4.36$ to 23.36 , one trial, 40 participants) respectively [10] (Figure 12, 13 \&14).

\section{Discussion}

No trial reported on neonatal death and this may indicate the relative safety of cesarean section particularly in the countries where the included studies conducted. Larger sample size would also be required to detect such outcome as most of the included studies were underpowered. In this review, spinal anesthesia appears to be associated with better first minute Apgar score (less than seven Apgar score) as compared to general Anesthesia. However, the mean Apgar score at first and fifth minute didn't show any significant difference when general anesthesia is compared with regional (spinal and epidural) anesthesia.

In pooled analysis, the umbilical arterial and venous $\mathrm{PH}$ were higher in regional anesthesia when compared to general anesthesia, but in other review [2] the Umbilical arterial PH didn't show any significant different unlike the Umbilical venous $\mathrm{PH}$ which is in line with this review.

The early neonatal neurobehavioral score was higher in spinal anesthesia as compared to general anesthesia. However, neonatal neurobehavioral Adaptive Capacity score at $15 \mathrm{~min}, 2 \mathrm{hr}$ and $24 \mathrm{hr}$ didn't show any significant difference between general and spinal anesthesia.

Incidence of neonatal ICU admission was higher in spinal anesthesia unlike a systemic review conducted by Cochrane collaboration where neonatal ICU admission is higher in general anesthesia as compared to regional (spinal and epidural) anesthesia and this discrepancy might be due to the low power in this review.

Need for resuscitation was significantly associated with general anesthesia when compared with regional anesthesia. However, a systemic review conducted by Cochrane collaboration didn't show any significant difference when general anesthesia is compared to regional (spinal and epidural) anesthesia [2]. Although regional anesthesia is associated with better neonatal outcomes, there is insignificant difference on neonatal outcomes when general anesthesia is compared with regional anesthesia in elective and semi-urgent cesarean section.

\section{Conclusion}

This review shows that Regional Anesthesia (epidural and spinal) is superior over general Anesthesia in certain neonatal outcomes as depicted by the pooled analysis of individual trials. However, there should be further review with individual trials having high power and similar dosage and techniques as most of the individual trials in this review are low powered and different types of outcome assessment techniques which brings high risk of bias and heterogeneity and difficult to come up with strong conclusion. Overall, the choice of Anesthesia technique for cesarean section would depend on the resource availability, set up of the institution and the skill of the Anesthesiology professional.

\section{Acknowledgements}

The authors thank Dr. Henok Taddesse for his valuable encouragement in the development and accomplishment of this research project.

\section{References}

[1]. Barash Paul G, Cullen Bruce F, Stoelting, Robert K, Cahalan Michael K , Stock M Christine (2009) Handbook of Clinical Anesthesia. (6th edn), Lippincott Williams \& Wilkins, Philadelphia. 697-702.

[2]. Afolabi BB, Lesi FEA, Merah NA (2006) Regional versus general anesthesia 
for caesarean section. Cochrane Database Syst Rev 4: 1-7.

[3]. Tabassum R, Sabbar S, Khan fa, Shaikh JM (2010) Comparison of the effects of general and spinal anaesthesia on apgar score of the neonates in patients undergoing elective caesarean section: pak j surg 26(1): 46-49

[4]. Solangi SA, Siddiqui SM, Khaskheli MS, Siddiqui MA (2012) Comparison of the effects of general vs spinal anesthesia on neonatal outcome. Anaesth Pain \& Intensive Care16 (1): 18-23.

[5]. Kosam d, kosam a and murthy m (2014) Effect of various techniques of anesthesia in elective caesarian section on short term neonatal outcome. international journal of medical research and review 2(5): 480-486.

[6]. N aye, ertu z, yilmaz $m$ and erman $m$ (2003) The effects of epidural anesthesia and general anesthesia on newborns at cesarean section. turkish journal of medical sciences 33: 311-314.

[7]. Akyol A, Akgun A, Gedikbasi A, Agrali G, Ceylan Y (2006) Effects of general and spinal anesthesia on APGAR scores and Umbilical cord blood gases in elective cesarean operations. Cochrane register of controlled trials. 20(1): 32-37.

[8]. Imtiaz A, Mustafa S, Haq N, Ali S, Imtiaz k (2009) Effect of spinal and general anaesthesia over apgar score in neonates born after elective cesarean section. jlumhs 9(3): 151-154.

[9]. I Ais, Ii öö, Iii ig, Iv he, V Em et al., (2015) Comparison of maternal and fetal outcomes among patients undergoing cesarean section under general and spinal anesthesia : a randomized clinical trial comparação dos resultados maternos e fetais em pacientes submetidos a cesariana sob anestesia geral e raquianestesia : um ensaio clínico randomizado.sao paulo med j 133(3): 227-234.

[10]. Abboud Tk, Nagappala S, Murakawa K, David S, Haroutunian S et al., (1985) Comparison of the effects of general and regional anesthesia for cesarean section on neonatal neurologic and adaptive capacity scores. journal of anesthesia analgesia 64(10): 996-1000.

[11]. Kolatat T, Somboonnanonda a, lertakyamanee j, Chinachot T, Tritrakarn T et al., (1999). Effects of general and regional anesthesia on the neonate. $j$ med assoc Thai 82(1):40-45.

[12]. Tonni G, Ferrari B, Felice C de, Ventura A (2007) Fetal acid-base and neonatal status after general and neuraxial anesthesia for elective cesarean section. international journal of obstetrics and gynecology 97(2): 143-146.
[13]. Martin TC, Bell P, Ogunbiyi O (2007) Comparison of general anaesthesia and spinal anaesthesia for caesarean section. west indian medical journal 56(4): 330-333.

[14]. Sungur Mo, Karaden M, Kili M, Seyhan Z (2013) Spinal anesthesia for elective cesarean section is associated with shorter hospital stay compared to general anesthesia 25(2): 55-63.

[15]. Saatsaz S, Moulookzadeh S, Rezaei R, Khani N (2014) Comparison of neonatal apgar score in general. indian journal of fundamental amd applied life science 4(3): 351-357.

[16]. Jawad zahir, Shazia Syed, Nadia Jabeen, Qudsia Anjum, Shafiq Ur et al., (2011) Maternal and neonatal outcome after spinal versus general anaesthesia for caesarean delivery. ann. pak. inst. med. Sci 7(3): 115-118.

[17]. Rasooli S, Moslemi F (2014) Apgar scores and cord blood gas values on neonates from cesarean with general anesthesia and spinal anesthesia. journal of anal research clinical medicine 2(1): 11-16. doi:10.5681/jarcm.2014.002.

[18]. Visalyaputra S, Rodanant O, Somboonviboon W, Tantivitayatan K, Thienthong S et al., (2005) Spinal versus epidural anesthesia for cesarean delivery in severe preeclampsia: a prospective randomized, multicenter study. anesth analg 101(3):862-868

[19]. Chattopadhyay S, Das a, Pahari S (2014) Fetomaternal outcome in severe preeclamptic women undergoing emergency cesarean section under either general or spinal anesthesia. Journal of Pregnancy Volume, Article ID 325098

[20]. Ahsan-ul-haq M (2004) Analysis of outcome of general versus spinal anaesthesia for caesarean delivery in severe pre-eclampsia with foetal compromise. Journal of biomedical 20: 1-8. 